\title{
The role of polyphenolic compounds in the diet as inhibitors of platelet function
}

\author{
Gary P. Hubbard ${ }^{1,2 *}$, Siegfried Wolffram ${ }^{3}$, Julie A. Lovegrove ${ }^{1}$ and Jonathan M. Gibbins ${ }^{2}$ \\ ${ }^{1}$ School of Food Biosciences and ${ }^{2}$ School of Animal and Microbial Sciences, University of Reading, \\ Whiteknights, Reading, Berks. RG6 6AL, UK \\ ${ }^{3}$ Institute of Animal Nutrition, Physiology and Metabolism, University of Kiel, D-24098 Kiel, Germany
}

\begin{abstract}
Platelets play a substantial role in cardiovascular disease, and for many years there has been a search for dietary components that are able to inhibit platelet function and therefore decrease the risk of cardiovascular disease. Platelets can be inhibited by alcohol, dietary fats and some antioxidants, including a group of compounds, the polyphenols, found in fruits and vegetables. A number of these compounds have been shown to inhibit platelet function both in vitro and in vivo. In the present study the effects of the hydroxycinnamates and the flavonoid quercetin on platelet activation and cell signalling in vitro were investigated. The hydroxycinnamates inhibited platelet function, although not at levels that can be achieved in human plasma by dietary intervention. However, quercetin inhibited platelet aggregation at levels lower than those previously reported. Quercetin was also found to inhibit intracellular $\mathrm{Ca}$ mobilisation and whole-cell tyrosine protein phosphorylation in platelets, which are both processes essential for platelet activation. The effect of polyphenols on platelet aggregation in vivo was also investigated. Twenty subjects followed a low-polyphenol diet for $3 \mathrm{~d}$ before and also during supplementation. All subjects were supplemented with a polyphenol-rich meal every lunchtime for $5 \mathrm{~d}$. Platelet aggregation and plasma flavonols were measured at baseline and after $5 \mathrm{~d}$ of dietary supplementation. Total plasma flavonoids increased significantly after the dietary intervention period $(P=0.001)$. However, no significant changes in ex vivo platelet aggregation were observed. Further investigation of the effects of individual polyphenolic compounds on platelet function, both in vitro and in vivo, is required in order to elucidate their role in the relationship between diet and the risk of cardiovascular disease.
\end{abstract}

Dietary polyphenols: Hydroxycinnamates: Quercetin: Platelet function: Risk for cardiovascular disease

Cardiovascular disease encompasses a large number of diseases of the heart and vascular system a large proportion of which arise as a result of two pathophysiological processes, i.e. atherosclerosis and thrombosis. Platelets play a major role in thrombosis, and platelet aggregation is promoted at sites of atheroma formation. The modulation of platelet activity using specific pharmacological agents has proven to be a successful strategy for the prevention of thrombosis. In recent years a number of dietary sources of inhibitors of platelet function have been reported (Calzada et al. 1997; Cerbone et al. 1999; Serebruany et al. 2000), although the relationship between diet and platelet function remains unresolved.

\section{Platelets}

Platelets circulate in the bloodstream, and play a pivotal role in both health and disease. Their main function is that of haemostasis. The haemostatic mechanisms have a number of important functions: (1) to maintain blood in a fluid state whilst it is in circulation around the body in the vascular system; (2) to arrest bleeding at the site of vascular injury or blood loss by forming a haemostatic plug; (3) to ensure the eventual removal of the haemostatic plug. Platelets are not activated if they are in contact with healthy vascular endothelium due to a combination of control mechanisms exerted by the endothelial cells, such as the synthesis of 
prostacyclin, the capacity to bind thrombin and activate the protein $\mathrm{C}$ system, and the ability to inactivate vasoactive substances such as serotonin and bradykinin. When the endothelium is damaged at the site of vascular injury components of the subendothelium, such as collagen, are exposed. Platelets adhere to the subendothelial components and become activated via cell signalling pathways, resulting in shape change, secretion and aggregation. The aggregated platelets form a plug covering the site of damage, which is further consolidated by components of the coagulation system (Hoffbrand \& Pettit, 1995).

\section{Polyphenolic antioxidants}

The polyphenols constitute one of the most numerous and ubiquitous groups of chemicals found in higher plants, and are an integral component of both the human and animal diet. The polyphenols encompass a large number of compounds that range from simple phenolic acids (such as the hydroxycinnamates) to complex polymers (such as the flavonoids and tannins). Plant polyphenols are essential to normal plants. They are involved in plant reproduction and growth, and provide plants with protection against pathogens. The polyphenol content of plants differs between species, and indeed between varieties of the same species (Bravo, 1998; Hollman \& Arts, 2000). There are $>8000$ phenolic structures currently known that are formed as a result of the secondary metabolism of plants. The flavonoids represent the most common and widely distributed group of plant phenolic compounds. Their common structure consists of two aromatic rings linked through three carbons that usually form an oxygenated heterocycle. Among the classes of flavonoids, those most commonly found are the flavones (e.g. apigenin, luteolin), the flavonols (e.g. quercetin, myricetin, kaempferol) and their glycosides. The flavonoids have been reported to exhibit a wide range of biological effects in animals and man that include antibacterial, antiviral, anti-carcinogenic, anti-inflammatory, anti-allergic anti-thrombotic and antioxidant activity (Bravo, 1998; Vinson, 1998; Hollman \& Arts, 2000). Quercetin, the structure of which is shown in Fig. 1, is a major flavonoid and has a wide spectrum of pharmacological effects. Quercetin has been shown to inhibit LDL oxidation in vitro (O'Reilly et al. 2000) and cause vasodilation in rat aortic strips (Zhao et al. 1999).
The dietary intake of the polyphenols, and particularly the flavonoids, has been studied in different countries, and varies greatly around the world. In the Seven Countries Study (Hertog et al. 1995) the average intake in west Finland was found to be $2.6 \mathrm{mg} / \mathrm{d}$, whereas in Japan the intake was $70 \mathrm{mg} / \mathrm{d}$. In the UK the intake of flavonols (a subgroup of the flavonoids) has been estimated from the Caerphilly (Wales) study to be $26 \mathrm{mg} / \mathrm{d}, 82 \%$ of which was provided by tea (Hertog et al. 1997).

The flavonoids are present in nearly all plant-derived food and beverage products. For instance, the flavonoid quercetin is found in particularly high levels in apples, onions, wine, tea, kale, broccoli and a number of berries (Hertog et al. 1992).

\section{The hydroxycinnamates}

The hydroxycinnamic acids are a series of trans-phenyl3-propionoic acids, differing in their ring substitutions. These compounds are widely distributed in plant material, including many foods and beverages. The hydroxycinnamates most commonly found are caffeic acid, ferulic acid, sinapic acid, $p$-coumaric acid and trans-cinnamic acid, the structures of which are shown in Fig. 2 (Clifford, 1999; Kroon \& Williamson, 1999).<smiles>O=c1c(O)c(-c2ccc(O)c(O)c2)oc2cc(O)cc(O)c12</smiles>

Fig. 1. Chemical structure of the flavonol quercetin. Quercetin has the typical two phenolic ring flavonoid structure and has a number of hydroxyl side chain groups, which confer on the molecule its high antioxidant activity.<smiles>COc1cc(/C=C/C(=O)O)cc(OC)c1O</smiles>

Sinapic acid<smiles>O=C(O)/C=C/c1ccccc1</smiles>

trans-Cinnamic acid<smiles>O=C(O)/C=C/c1ccc(O)cc1</smiles>

p-Coumaric acid<smiles>COc1cc(/C=C/C(=O)O)ccc1O</smiles>

Ferulic acid<smiles>O=C(O)/C=C/c1ccc(O)c(O)c1</smiles>

Caffeic acid

Fig. 2. Chemical structure of the five most common hydroxycinnamates. The hydroxycinnamates all have a single phenolic ring structure and differ in their side chain groups. 
Blueberries (Vaccinium spp.), aubergines (Solanum melongena), wine, grape juice, coffee, apples and citrus juices provide sources of hydroxycinnamates (Clifford, 2000). There are data for dietary intake of hydroxycinnamates from a German study, which investigated the phenolic acid intake of adults in a Bavarian sub-population (Radtke et al. 1998). In this study a database of the phenolic content of foods was compiled and used in conjunction with diet diaries to estimate the phenolic acid intake of 119 men and women over a 1 -week period. The mean daily intakes of total phenolic acids and total cinnamic acids were 222 and $211 \mathrm{mg}$ respectively, to which caffeic acid $(206 \mathrm{mg} / \mathrm{d})$ made the greatest contribution. In this study coffee and fruits were the main sources of hydroxycinnamates.

\section{The bioavailability of polyphenols}

The bioavailability of foods relates to the amount of a certain component within ingested food that is able to cross the gut wall and enter the bloodstream, where it may then have a biological effect. However, these components may have been subject to several metabolic transformations within the intestinal mucosa and liver (first pass effects) that may influence their biological potential. Furthermore, the chemical form of polyphenols present in food (e.g. the sugar moiety of flavonoid glycosides) as well as interactions with the food matrix may have profound effects on the bioavailability.

In a study carried out by Conquer et al. (1998) twentyseven men and women were given quercetin-containing capsules supplying $1 \mathrm{~g}$ quercetin/d or a placebo for $28 \mathrm{~d}$. Plasma quercetin levels rose from 0.08 (SE 0.08) $\mu \mathrm{M}$ to 1.3 (SE 0.28) $\mu \mathrm{M}$. In another study (McAnlis et al. 1999) five subjects ingested $225 \mathrm{~g}$ fried onions (Allium cepa), and blood samples were taken after the meal. Plasma quercetin levels were found to peak at 0.77 (SE 0.3) $\mu \mathrm{M} 2 \mathrm{~h}$ after the meal. Although no detailed information about the bioavailability of quercetin can be derived from these two examples, they demonstrate that quercetin is indeed absorbed and that intake of quercetin-containing foods influences plasma levels of this flavonol. There are also data for the bioavailability of the hydroxycinnamates, including a human dietary study (Bourne \& Rice-Evans, 1999) in which four healthy volunteers were supplemented with tomatoes (Lycopersicon esculentum; $8 / \mathrm{g} / \mathrm{kg}$ body weight) providing $21-44 \mathrm{mg}$ ferulic acid. Urine samples were collected for $24 \mathrm{~h}$ after consumption and analysed for ferulic acid content. The total free ferulic acid excreted in $8-10 \mathrm{~h}$ was $1 \cdot 9-3 \cdot 4 \mu \mathrm{M}$, approximately $4-5 \%$ of the ferulic acid ingested. The polyphenols are very difficult to detect in human and animal tissues, which can be problematic in bioavailability studies.

\section{The role of antioxidants in heart disease}

Antioxidants have received attention in recent years as a possible mechanism by which dietary components protect the body from free radicals and reactive oxygen species. These oxidative agents are thought to play a role in many disease states, such as cancer and atherosclerosis (Holvoet \& Collen, 1994). Observational studies have shown that individuals who consume large amounts of fruit and vegetables have lower rates of CHD (Hertog et al. 1993). This outcome has been attributed to the high levels of antioxidant vitamins found in these foods. One such study is the Oxford Vegetarian study, which was carried out between 1980 and 1993 and included 6115 vegetarian subjects and 5015 meat-eating subjects. The death rate from CHD among the vegetarians was half that of the meat eaters. However, after adjustment for confounding factors, such as BMI, smoking and social class, this difference was no longer significant (Thorogood, 1997).

A number of dietary antioxidants found in fruit and vegetables, such as vitamin $\mathrm{E}$, vitamin $\mathrm{C}$ and the polyphenols, have also been shown to be associated with a decreased risk of CHD. The vitamin E intake of $>39000$ male health-care professionals was investigated for 4 years (Rimm et al. 1996), and those subjects with a dietary intake of vitamin $E$ between 100 and $249 \mathrm{mg} / \mathrm{d}$ had a $50 \%$ decreased relative risk of CHD. The effect of vitamin $\mathrm{C}$ intake on CHD risk was investigated in the Finnish Mobile Clinic Study (Knekt et al. 1994). In this study high vitamin $C$ intake was associated with a reduced risk of CHD mortality in women but not in men. Women with a vitamin C intake of $>91 \mathrm{mg} / \mathrm{d}$ had a $50 \%$ decreased relative risk of CHD mortality compared with those with a lower intake.

There have been a number of studies in which the relationship between the intake of polyphenols and CHD risk has been investigated. The Zutphen Study carried out in The Netherlands assessed the intake of flavonoids (a subgroup of the polyphenols) of 805 men aged 65-84 years in 1985, with a 5-year follow up. The subjects were grouped according to flavonoid intake $(\mathrm{mg} / \mathrm{d})$ : high $>30$, medium 19-29, low $<19$. The relative risk of both CHD and myocardial infarction was significantly lower in the medium- and high-flavonoid intake groups $(P=0 \cdot 015)$. These effects were attributed to the flavonoids present in tea, apples and onions, which provide the major sources of flavonoids in the Dutch diet (Hertog et al. 1993).

\section{Inhibition of platelet function by antioxidants}

In view of the importance of the role of platelets in heart disease, there has been a large amount of research committed to understanding platelet function and the role of platelets in disease. This research has concentrated on finding compounds that can inhibit platelet function and, therefore, decrease the likelihood of thrombosis and thus heart disease. Platelets can be inhibited by a number of dietary components. The dietary antioxidants vitamins $\mathrm{C}$ and E (Salonen et al. 1991; Freedman et al. 1996) and the flavonoids have been shown to have inhibitory effects on platelet function in vitro and in vivo.

The in vitro inhibitory effects of the flavonoids on platelet aggregation have been extensively investigated (Beretz et al. 1982; Landolfi et al. 1984). Beretz et al. (1982) studied thirteen different flavonoids, with thrombin, collagen and ADP as agonists. The most potent inhibitor of platelet aggregation was found to be phloretin (median inhibitory concentration $\left(\mathrm{IC}_{50}\right) 13 \mu \mathrm{M}$, with collagen $(2.5 \mu \mathrm{g} / \mathrm{ml})$ as the agonist). Landolfi et al. (1984) studied fifteen different flavonoids with arachidonic acid and collagen as agonists. This study reported flavone $\left(\mathrm{IC}_{50}\right.$ 


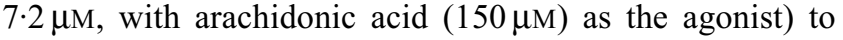
be the most potent inhibitor of platelet aggregation. The $\mathrm{IC}_{50}$ values for quercetin with collagen as the agonist were $55 \mu \mathrm{M}$ (Beretz et al. 1982) and $>200 \mu \mathrm{M}$ (Landolfi et al. 1984).

There is also evidence for in vivo inhibition of platelet aggregation by flavonoids from dietary sources. Keevil et al. (2000) supplemented ten subjects with purple-grape juice, orange juice or grapefruit juice $(5 \cdot 0-7 \cdot 5 \mathrm{ml} / \mathrm{kg}$ per d) for 1 week in a randomised cross-over study. Drinking purple-grape juice for 1 week reduced whole-blood platelet aggregation in response to collagen $(1.0 \mu \mathrm{g} / \mathrm{ml})$ by $77 \%$. However, consumption of orange juice or grapefruit juice had no effect on platelet aggregation. The purple-grape juice was found to have three times the polyphenolic content of the other two juices, whereas the vitamin $\mathrm{C}$ levels were similar for all three juices (Keevil et al. 2000). Similarly, Janssen et al. (1998) carried out in vivo supplementation studies with quercetin, in the form of onions. Eighteen volunteers were fed $220 \mathrm{~g}$ onions/d (providing $114 \mathrm{mg}$ quercetin/d) or placebo, each for $7 \mathrm{~d}$, in a randomised crossover experiment. In this study plasma quercetin levels were raised to $1.5 \mu \mathrm{mol} / 1$. Platelet aggregation for subjects supplemented with onions was inhibited by $7.6 \%$ with collagen $(2.0 \mu \mathrm{g} / \mathrm{ml})$ as agonist and $14 \%$ with ADP $(3.0 \mu \mathrm{M})$ as agonist, the results were not statistically significant (Janssen et al. 1998). While these studies investigated the effects of polyphenolic compounds derived from food on platelet aggregation, Conquer et al. (1998) investigated the effects of flavonoid supplementation in the form of capsules. In this study twenty-seven subjects ingested $1 \mathrm{~g}$ quercetin and $1 \mathrm{~g}$ mixed flavonoids/d or placebo for $28 \mathrm{~d}$. Plasma quercetin concentrations increased from $0 \cdot 10 \mu \mathrm{M}$ (SE 0.09) before supplementation to $1.5 \mu \mathrm{M}$ (SE $0 \cdot 30$ ) after the $28 \mathrm{~d}$ supplementation period. Platelet aggregation was also measured before and after supplementation, with collagen $(10 \mu \mathrm{g} / \mathrm{ml})$ as agonist, and no significant changes in platelet aggregation were observed with quercetin supplementation (Conquer et al. 1998).

The present study investigated the effects of five hydroxycinnamates and quercetin on platelet aggregation in vitro and examined possible mechanisms for this inhibitory action. In addition, a human dietary study is described in which the effects of a diet rich in fruit and vegetables on platelet aggregation were analysed.

\section{Methods \\ Materials}

Quercetin dihydrate, ferulic acid, trans-cinnamic acid, $p$-coumaric acid, sinapic acid and caffeic acid were purchased from Sigma (Poole, Dorset, UK) and solubilised in dimethylsulphoxide, also purchased from Sigma. HormChemie collagen (collagen fibres from equine tendons) was purchased from Nycomed (Munich, Germany). Antiphosphotyrosine monoclonal antibody (4G10) was obtained from Upstate Biotechnology (TCS Biologicals, Botolph Claydon, Bucks., UK). Horseradish peroxidase conjugated secondary antibodies and the enhanced chemiluminescence detection system were purchased from Amersham Biosciences (Little Chalfont, Bucks., UK). Fura-2 AM was obtained from Molecular Probes (Cambridge Bioscience, Cambridge, UK). ADP was purchased from Chrono-log Corporation (Havertown, PA, USA). All other reagents were obtained from sources previously described (Gibbins et al. 1998; Cicmil et al. 2000).

\section{Preparation and stimulation of platelets for in vitro studies}

Human platelets from healthy aspirin-free volunteers were prepared on the day of the experiment by differential centrifugation as described previously (Gibbins et al. 1998) and suspended in modified Tyrodes-Hepes buffer $\left(134 \mathrm{~mm} \mathrm{NaCl}, 0.34 \mathrm{mM} \mathrm{Na} \mathrm{HPO}_{4}, 2 \cdot 9 \mathrm{mM} \mathrm{KCl}, 12 \mathrm{mM}\right.$ $\mathrm{NaHCO}_{3}, 20 \mathrm{~mm}$ Hepes, $5 \mathrm{~mm}$ glucose, $1 \mathrm{mM} \mathrm{MgCl}_{2}, \mathrm{pH} 7 \cdot 3$ ) to a density of $2 \times 10^{8}$ cells $/ \mathrm{ml}$ for aggregation experiments. Stimulation of platelets $(450 \mu \mathrm{l})$ with collagen $(50 \mu \mathrm{l})$ was performed at $37^{\circ}$ using an optical platelet aggregometer (Chrono-log Corporation) with continuous stirring (1200 rpm; Born, 1962). Platelets were incubated with polyphenol dissolved in dimethylsulphoxide $(1 \mu \mathrm{l})$ or with dimethylsulphoxide alone $(0 \cdot 2 \%(\mathrm{v} / \mathrm{v}) ; 1 \mu \mathrm{l})$ for $5 \mathrm{~min}$ (after stirring for $10 \mathrm{~s}$ ) followed by stimulation with collagen for $90 \mathrm{~s}$. For immunoblotting experiments, platelets were suspended at $8 \times 10^{8}$ cells $/ \mathrm{ml}$ in buffer containing $1 \mathrm{mM}$ ethylene glycol- $O,-O^{\prime}$-bis(2-amino-ethyl)- $N, N, N^{\prime}, N^{\prime}$-tetraacetic acid to prevent aggregation. Hence, the concentration of collagen was increased to $25 \mu \mathrm{g} / \mathrm{ml}$ for the observation of tyrosine phosphorylation events. Polyphenol concentrations were therefore increased proportionately. Platelet stimulation was terminated by the addition of an equal volume of ice-cold NP40 lysis buffer (Nonidet P40; $20 \mathrm{mM}$-Tris, $300 \mathrm{mM}-\mathrm{NaCl}, 10 \mathrm{~mm}$-EDTA, $1 \mathrm{mM}$-phenylmethylsulfonyl fluoride, $2 \mathrm{mM}-\mathrm{Na}_{3} \mathrm{VO}_{4}, 10 \mu \mathrm{g} / \mathrm{ml}$ leupeptin, $10 \mu \mathrm{g} / \mathrm{ml}$ aprotonin, $1 \mu \mathrm{g} / \mathrm{ml}$ pepstatin A, pH 7·3; $\%$, v/v). Detergentinsoluble debris was removed by centrifugation and proteins were separated by SDS-PAGE under reducing conditions using $10 \%(\mathrm{v} / \mathrm{v})$ gels and transferred to polyvinylidene difluoride membranes by semi-dry Western blotting.

\section{Immunoblotting}

Membranes were blocked by incubation in bovine serum albumin $(10 \%, w / v)$ dissolved in Tris-buffered salineTween (20 mM-Tris, $137 \mathrm{~mm}-\mathrm{NaCl}$, Tween $20(0 \cdot 1 \%$, $\mathrm{v} / \mathrm{v}), \mathrm{pH} 7 \cdot 6)$. Primary and secondary antibodies were diluted in Tris-buffered saline-Tween containing bovine serum albumin $(2 \%, \mathrm{w} / \mathrm{v})$ and incubated with membranes for $1 \mathrm{~h}$ at room temperature with rotation. Blots were washed for $2 \mathrm{~h}$ in Tris-buffered saline-Tween following each of the incubations with antibodies and then developed using an enhanced chemiluminescence detection system. Anti-phosphotyrosine antibody (4G10) was used at a concentration of $1 \mu \mathrm{g} / \mathrm{ml}$ and horseradish peroxidase-conjugated secondary antibody (anti-mouse-IgG-horseradish peroxidase) was diluted 1:10000. Densitometry analysis was carried out using a Bio-Rad GS710 densitometer with Quantity One analysis software (Bio-Rad, Hemel Hempstead, Herts., UK). 


\section{Measurement of intracellular calcium ion concentration by spectrofluorimetry}

Washed human platelets (as described earlier) were incubated at $2 \times 10^{9}$ cells $/ \mathrm{ml}$ in $\mathrm{Ca}^{2+}$-free Tyrodes-Hepes buffer with $3 \mu \mathrm{M}$-Fura-2 AM for 45 min. Platelets were washed once and resuspended at $2 \times 10^{8}$ cells $/ \mathrm{ml}$ in modified Tyrodes-Hepes buffer. Platelets were incubated with quercetin or dimethylsulphoxide alone (as described earlier) for $5 \mathrm{~min}$ and then stimulated with collagen $(5.0 \mu \mathrm{g} / \mathrm{ml})$ with constant stirring at $37^{\circ}$ in a luminescence spectrophotometer (LS-50B, Perkin Elmer, Beaconsfield, Bucks., UK) with excitation wavelengths of $340 \mathrm{~nm}$ and $380 \mathrm{~nm}$. Fluorescence emission was measured at a wavelength of $510 \mathrm{~nm}$. The ratio of emission values $(340 \mathrm{~nm}: 380 \mathrm{~nm})$ was calculated and converted to $\mathrm{Ca}^{2+}$ concentration using FLWinLab software (Perkin Elmer) and the equation:

$$
\left[\mathrm{Ca}^{2+}\right]_{\mathrm{i}}=\left(K_{d} \times\left(\mathrm{R}-\mathrm{R}_{\min }\right)\right) \div\left(\left(\mathrm{R}_{\max }-\mathrm{R}\right) \times \mathrm{SFB}\right),
$$

where $\left[\mathrm{Ca}^{2+}\right]_{\mathrm{i}}$ is the intracellular $\mathrm{Ca}^{2+}$ concentration, $\mathrm{R}$ is the value for the emission ratio $(340 \mathrm{~nm}: 380 \mathrm{~nm}), \mathrm{K}_{\mathrm{d}}$ is the dissociation constant of the Fura- $2-\mathrm{Ca}^{2+}$ complex (224 nM) and SFB is the fluorescence ratio at $340 \mathrm{~nm}: 380 \mathrm{~nm}$ of $R_{\min }$ and $R_{\max } \cdot R_{\max }$, the maximum $340 \mathrm{~nm}: 380 \mathrm{~nm}$ value, was determined by lysing platelets with NP40 immunoprecipitation lysis buffer in the presence of $1 \mathrm{mM}-\mathrm{CaCl}_{2}$. $\mathrm{R}_{\text {min, }}$ the minimum $340: 380 \mathrm{~nm}$ value, was determined by the addition of $2 \mathrm{mM}$-ethylene glycol- $O,-O^{\prime}$-bis(2-aminoethyl)- $N, N, N^{\prime}, N^{\prime}$-tetraacetic acid.

\section{Design of fruit- and vegetable-rich diet study}

Twenty subjects (ten male and ten female) were recruited from the University of Reading. The Ethics and Research Committee of the University of Reading approved the protocol and all subjects gave informed consent before taking part. For $3 \mathrm{~d}$ the subjects followed a fruit- and vegetable-free diet. A blood sample was taken at the end of the $3 \mathrm{~d}$, and the subjects were given a lunchtime meal of five portions of fruit and vegetables (Table 1) every day for the next $5 \mathrm{~d}$. At the end of this period another blood sample was taken. All subjects were asked to abstain from polyphenol-rich foods for the duration of the study, so that the only polyphenols in the diet were those in the fruit and vegetable meal. The subjects were given details of a diet low in polyphenols (Hertog et al. 1992), and they were asked to record all food and drink consumed throughout the $8 \mathrm{~d}$ of the study. A maximum of three cups of tea or coffee per $d$ was allowed and the amount consumed was noted in the diet diary.

The US Department of Agriculture (1992) Food Pyramid Guide suggests five or more servings of fresh fruit and vegetables per $d$. This recommendation was used as a guide for the design of a meal that contained five or more servings of fruit and vegetables that were high in polyphenols and also provided carbohydrate and protein. The composition of the meal is shown in Table. 1.

\section{Measurement of whole-blood platelet aggregation in samples from the fruit and vegetable study}

Blood samples were taken into $4.5 \mathrm{ml}$ vacutainer system blood tubes (Becton Dickinson, Plymouth, UK) containing
Table 1. Composition of fruit and vegetable meal given to subjects participating in the fruit- and vegetable-rich diet study*

\begin{tabular}{llc}
\hline Course & Food product & Weight $(\mathrm{g})$ \\
\hline Salad starter & Cherry tomatoes & 100 \\
& Cucumber & 60 \\
& Continental four-leaf salad & 25 \\
& Salad dressing & 4 \\
Main course & Tomato and onion pasta sauce & 175 \\
& $\quad$ composed of: & \\
& Yellow onions & approximately 70 \\
& Passata (sieved plum & approximately 105 \\
& $\quad$ tomatoes) & $>1$ \\
& Extra virgin olive oil & 75 or 125 \\
& Tricolour fusilli pasta (cooked & \\
Dessert & weight) & 100 \\
& Frozen raspberries (defrosted & 25 \\
& $\quad$ weight) & average 30 \\
Drink & Oanilla ice cream & $350 \mathrm{ml}$ \\
\hline
\end{tabular}

${ }^{*}$ For details of procedures, see p. 472.

†Subjects weighing $<60 \mathrm{~kg}$ were given $75 \mathrm{~g}$ pasta, those weighing $>60 \mathrm{~kg}$ were given $125 \mathrm{~g}$, unless otherwise requested.

$0 \cdot 105 \mathrm{M}$-sodium citrate as anticoagulant (1 vol. sodium citrate:9 vol. blood). Samples were stored at room temperature, and analysis was commmenced $1 \mathrm{~h}$ after venepuncture and completed within $4 \mathrm{~h}$.

Whole blood was diluted 1:1 (v/v) with PBS, followed by pre-incubation to $37^{\circ}$. Whole-blood platelet aggregation was measured for 6 min after stimulation with an agonist. The extent of aggregation was determined as the amplitude of the slope produced after the addition of the agonist (electrical impedance; $\Omega$ ).

\section{Plasma concentrations of flavonoids}

The plasma concentrations of flavonoids were determined as described previously (Ader et al. 2000), with minor modifications. Blood samples were taken into $10 \mathrm{ml}$ vacutainer system blood tubes with EDTA. Plasma was prepared by centrifugation for $10 \mathrm{~min}$ at $2000 \mathrm{~g}$, and stored at $-80^{\circ}$ until analysed. An aliquot $(800 \mu \mathrm{l})$ of the plasma sample was acidified with $100 \mu \mathrm{l}$ acetic acid $(0.583 \mathrm{~mol} / \mathrm{l})$, spiked with $20 \mu \mathrm{l}$ rhamnetin $(50 \mu \mathrm{g} / \mathrm{ml}$ in methanol; internal standard) and subsequently treated with a mixture of $\beta$-glucuronidase $\left(10^{4}\right.$ units)-sulphatase $\left(2.5 \times 10^{2}\right.$ units $)$; crude extract from Helix pomatia; Sigma-Aldrich AG, Deisenhofen, Germany. After an incubation of $1 \mathrm{~h}$ at $37^{\circ}$ the flavonol aglyca quercetin, kaempferol, isorhamnetin and tamarixetin were simultaneously extracted with $5.5 \mathrm{ml}$ acetone. The mixture was centrifuged at $3700 \mathrm{~g}$ for $45 \mathrm{~min}$ and the supernatant fraction was evaporated to dryness under vacuum at $45^{\circ}$ (SpeedVac AES 1010; Savant Instruments Inc., Farmindale, NY, USA). The residue was redissolved in $200 \mu \mathrm{l}$ methanol, $77.5 \mu \mathrm{l}$ deionised water and $22.5 \mu \mathrm{l} \mathrm{HCl}(10 \mathrm{~mol} / \mathrm{l})$. For HPLC analysis $30 \mu \mathrm{l}$ were injected onto a C-18 Kromasil 100 column $(250 \times 4 \mathrm{~mm}$, particle size $5 \mu \mathrm{m}$; Jasco, GrossUmstadt, Germany) protected by a C-18 Inertsil ODS-2 precolumn $(10 \times 4 \mathrm{~mm}, 5 \mu \mathrm{m}$ particle size; Jasco $)$. The eluent $(1 \mathrm{ml} / \mathrm{min})$ was $0.025 \mathrm{M}-\mathrm{NaH}_{2} \mathrm{PO}_{4}(\mathrm{pH} 2 \cdot 4)$-acetonitrile- 
methanol (68:27:5, by vol.). The column effluent was mixed with $1.5 \mathrm{M}-\mathrm{Al}\left(\mathrm{NO}_{3}\right)_{3}$ in methanol containing acetic acid $(7.5 \%, \mathrm{v} / \mathrm{v})$ at a rate of $0.4 \mathrm{ml} / \mathrm{min}$ in a post-column reactor $(3 \mathrm{~m}$ Tefzel-tube, $0.5 \mathrm{~mm}$ i.d., coiled to an outer diameter of $5 \mathrm{~mm}$ and connected to the HPLC column with a low-dead-volume tee; Jasco). The column and the reactor were placed in a column oven set at $30^{\circ}$. The fluorescence of the resulting flavonoid-metal complex was measured at 485 nm using a Jasco FP 920 (Jasco Corp) fluorescence detector with excitation wavelength set at $422 \mathrm{~nm}$. The limit of detection was $3 \mathrm{ng} / \mathrm{ml}$.

\section{Statistical analysis}

$\mathrm{IC}_{50}$ values were calculated using Prism for Windows version 2.0 (Graphpad Inc., San Diego, CA, USA) with nonlinear regression. Graphs were plotted using a sigmoidal curve, and variable Hill slope with $100 \%$ and $0 \%$ inhibition constants. Paired $t$ tests were performed using SPSS 10.0 for windows (SPSS, Chicago, IL, USA). Results are presented as mean values with their standard errors and $P \leq 0.05$ was considered significant.

\section{Results \\ In vitro effects of polyphenols on platelet function}

The effects of five different hydroxycinnamates and quercetin on platelet aggregation were investigated. Percentage inhibition of platelet aggregation was calculated and $\mathrm{IC}_{50}$ values determined. The $\mathrm{IC}_{50}$ values for the hydroxycinnamates are shown in Table 2. Sinapic acid had the highest $\mathrm{IC}_{50}$ value $(815(\mathrm{SE} 1.09) \mu \mathrm{M})$; all the other $\mathrm{IC}_{50}$ values were approximately $500 \mu \mathrm{M}$.

The $\mathrm{IC}_{50}$ values for quercetin with collagen (4, 2 and $0.5 \mu \mathrm{g} / \mathrm{ml}$ ) as agonist were ( $\mu \mathrm{M})$ 6.47 (SE 1.09), 4.87 (SE 1.11) and 2.37 (SE 1.03) respectively ( $n$ 3). The $\mathrm{IC}_{50}$ value for quercetin with thrombin $(0 \cdot 1 \mathrm{IU} / \mathrm{ml})$ as agonist was 27.6 (SE 1.04) $\mu \mathrm{M}\left(n\right.$ 3). The $\mathrm{IC}_{50}$ values for quercetin were all substantially lower than those for the hydroxycinnamates. The $\mathrm{IC}_{50}$ values were also dependent on the concentration of collagen used.

The effect of quercetin on the mobilisation of $\mathrm{Ca}$ from intracellular stores was investigated. Mean peak Ca concentrations are shown in Table 3. When platelets were incubated with varying concentrations of quercetin, mean peak $\mathrm{Ca}$

Table 2. Median inhibitory concentration $\left(\mathrm{IC}_{50}\right)$ values for the inhibition of platelet aggregation by five hydroxycinnamates with collagen $(1.0 \mu \mathrm{g} / \mathrm{ml})$ as agonist*

(Mean values with their standard errors for three determinations)

\begin{tabular}{lcc}
\hline & \multicolumn{2}{c}{$\mathrm{IC}_{50}(\mu \mathrm{M})$} \\
\cline { 2 - 3 } Hydroxycinnamate & Mean & SE \\
\hline Sinapic acid & 815.9 & 1.09 \\
trans-Cinnamic acid & 528.5 & 1.19 \\
p-Coumaric acid & 482.6 & 1.22 \\
Ferulic acid & 481.7 & 1.20 \\
Caffeic acid & 478.1 & 1.19 \\
\hline
\end{tabular}

${ }^{\star}$ For details of procedures, see p. 472.
Table 3. Inhibition of platelet calcium release by quercetin with collagen $(5.0 \mu \mathrm{g} / \mathrm{ml})$ as agonist.

(Mean values with their standard errors for three determinations)

\begin{tabular}{lcc}
\hline & \multicolumn{2}{c}{ Peak Ca concentration $(\mathrm{nM})$} \\
\cline { 2 - 3 } Quercetin $(\mu \mathrm{M})$ & Mean & SE \\
\hline 0 & 87.75 & 7.76 \\
5 & 75.84 & 13.7 \\
10 & 51.98 & 15.7 \\
15 & 21.73 & 4.96 \\
20 & 3.7 & 2.51 \\
\hline
\end{tabular}

*For details of procedures, see p. 472.

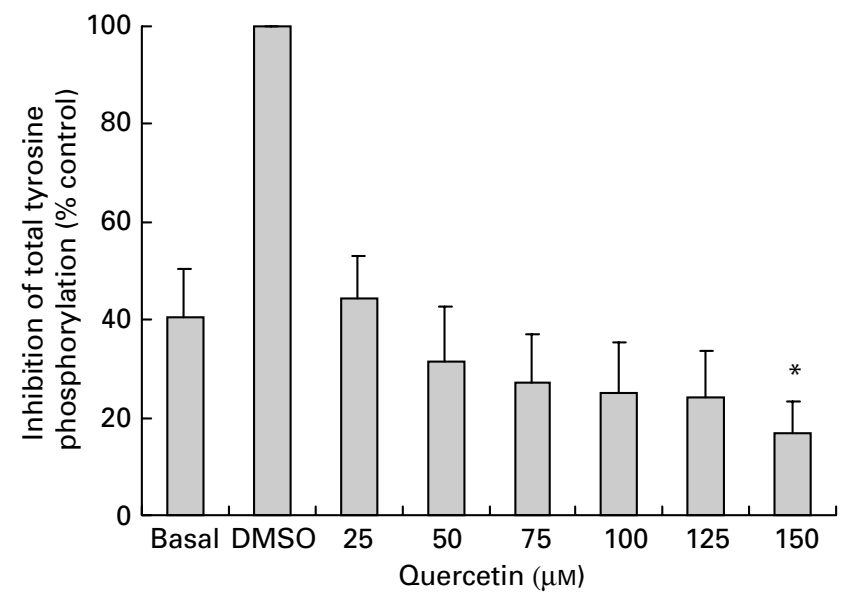

Fig. 3. Quercetin inhibits collagen-stimulated whole-cell proteintyrosine phosphorylation. Platelets, in the presence of ethylene glycol-O,-O'-bis(2-amino-ethyl)- $N, N, N^{\prime}, N^{\prime}$-tetraacetic acid (1 mM), were incubated with quercetin $(25-150 \mu \mathrm{M})$ or dimethylsulphoxide (DMSO) control for $5 \mathrm{~min}$ and then stimulated with collagen $(25 \mu \mathrm{g} / \mathrm{ml})$ for $90 \mathrm{~s}$. Platelets were then lysed and proteins separated by SDS-PAGE under reducing conditions and subjected to immunoblotting to detect protein phosphotyrosine residues. Total protein-tyrosine phosphorylation was analysed using densitometry. Total tyrosine phosphorylation is shown as a percentage of the control value. Values are means with their standard errors represented by vertical bars for three determinations. Mean value was significantly different from that for the dimethylsulphoxide control and from basal levels: ${ }^{*} P=0.05$.

release was inhibited in a concentration-dependent manner, and was almost completely abolished by $20 \mu \mathrm{M}$-quercetin.

The effect of quercetin on platelet whole-cell protein tyrosine phosphorylation was also investigated. Fig. 3 shows the total platelet whole-cell tyrosine protein phosphorylation as a percentage of the control value. Percentage total platelet whole-cell tyrosine phosphorylation increased from basal levels on stimulation with collagen, as previously reported (Gibbins et al. 1997). In the presence of quercetin, percentage total platelet whole-cell protein tyrosine phosphorylation was inhibited in a concentration-dependent manner. Quercetin at $150 \mu \mathrm{M}$ significantly inhibited percentage total platelet whole-cell tyrosine phosphorylation when compared with the dimethylsulphoxide control and basal levels $(P=0.05)$. 


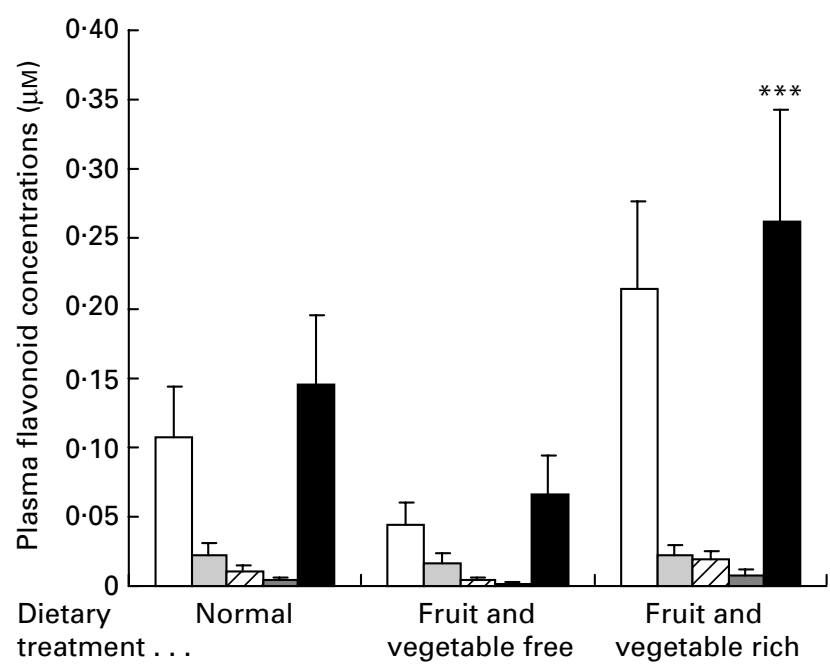

Fig. 4. The effect of polyphenolic content of the diet on plasma flavonol levels. The concentrations of four flavonols (quercetin $(\square)$,

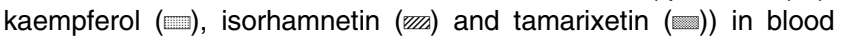
plasma from subjects consuming their normal diet, after $3 \mathrm{~d}$ on a low-polyphenol diet and after $5 \mathrm{~d}$ of supplementation of the low-polyphenol diet with a fruit- and vegetable-rich lunchtime meal every day were measured by HPLC (for details of diets and procedures, see p. 472). Total flavonol concentration $(\square)$ represents the sum of the concentrations of the four flavonols measured. Values are means with their standard errors represented by vertical bars for twenty subjects. Mean value was significantly different from that after the $3 \mathrm{~d}$ period on the fruit- and vegetable-free diet: ${ }^{* *} P=0.001$

\section{The effects of a fruit and vegetable-rich diet on platelet aggregation}

Plasma concentrations of quercetin, kaempferol, isorhamnetin and tamarixetin were measured as markers of polyphenolic intake. The mean plasma concentrations of these polyphenols are shown in Fig. 4. Plasma concentrations of the four flavonol compounds were measured on entry to the study (i.e. under normal dietary conditions), after the fruit- and vegetable-free period and after the fruitand vegetable-enriched period. The total plasma flavonol concentration showed a decrease after the $3 \mathrm{~d}$ fruit- and vegetable-free period compared with that for the normal diet (from 0.154 $\mu \mathrm{M}$ (SE 0.027) to $0.071 \mu \mathrm{M}$ (SE 0.015)), but increased significantly (from $0.071 \mu \mathrm{M}$ (SE 0.015) to $0.277 \mu \mathrm{M}($ SE 0.044$) ; P=0.001)$ after supplementation with the fruit- and vegetable-rich lunchtime meal for $5 \mathrm{~d}$. Quercetin concentrations were the highest of the four compounds detected and constituted $80 \%$ of the total levels.

Platelet aggregation was measured as whole-blood platelet aggregation with two different agonists (ADP and collagen) after the fruit- and vegetable-free period and after the fruit- and vegetable-supplementation period for the twenty subjects. After the supplementation period the mean whole-blood platelet aggregation had decreased from 13.56 (SE 0.54) $\Omega$ to $12 \cdot 32$ (SE 0.78) $\Omega$ with $\operatorname{ADP}(10 \mu \mathrm{M})$ and from 13.35 (SE 1.60) $\Omega$ to 12.9 (SE 1.57) $\Omega$ with collagen $(1.5 \mu \mathrm{g} / \mathrm{ml})$. However, these changes were not significant.
When a higher dose of collagen $(5.0 \mu \mathrm{g} / \mathrm{ml})$ was used as the agonist the mean whole-blood platelet aggregation after the supplementation period was unchanged.

\section{Discussion}

The dietary antioxidants found in fruits and vegetables have received attention in recent years as a possible mechanism by which dietary components protect the body from free radicals and reactive oxygen species. These dietary antioxidants may therefore play a role in many disease states, such as atherosclerosis. Platelet function can be regulated by a number of pharmacological agents, including a number of compounds that are found in the diet (Cerbone et al. 1999; Serebruany et al. 2000). A group of polyphenolic antioxidants of the flavonoid family have been shown to inhibit platelet aggregation in vitro (Beretz et al. 1982; Landolfi et al. 1984; Tzeng et al. 1991) and some human dietary studies have also suggested that a diet high in flavonoids may inhibit platelet aggregation in vivo (Janssen et al. 1998; Keevil et al. 2000). Quercetin, a flavonoid that has received much attention in the area of nutritional biology, has been shown to inhibit platelet aggregation in vitro (Beretz et al. 1982). Although a specific mechanism for this inhibitory activity has not been established, a number of investigations of possible mechanisms have been reported. Certain flavonoids have been shown to inhibit the generation of metabolites of arachidonic acid by cyclooxygenase and lipoxygenase (Beretz et al. 1982; You et al. 1999), and inhibit Ca-dependent isoforms of protein kinase C (Liu \& Liang 2000). However, platelet function is controlled by a network of signalling pathways, and the exact mode of action has not been elucidated.

In the present study the effects of the hydroxycinnamates (a subgroup of the polyphenols) and the flavonol quercetin on platelet aggregation in vitro were investigated. The hydroxycinnamates were found to inhibit platelet aggregation with collagen as an agonist. However, the concentrations of hydroxycinnamates required $(556 \mu \mathrm{M}$ is the average concentration required to produce a $50 \%$ inhibition of platelet aggregation) were higher than those reported to be present in human plasma (approximately $3 \mu \mathrm{M}$; Bourne \& Rice-Evans, 1998, 1999). Thus, the hydroxycinnamates would not appear to make a marked contribution to reduced platelet function in vivo.

Consistent with previous reports (Beretz et al. 1982), quercetin was shown to inhibit collagen-induced platelet aggregation in vitro in a concentration-dependent manner. This effect was also dependent on the concentration of collagen used, with higher concentrations of quercetin being required to overcome stimulation by higher concentrations of collagen. The $\mathrm{IC}_{50}$ values for quercetin found in the present study are lower than those published previously (Beretz et al. 1982; Landolfi et al. 1984), and are the same, or close to, quercetin concentrations that may be present in the human plasma, which can be as high as $3.5 \mu \mathrm{M}$ after ingestion of certain forms of quercetin (Hollman et al. 1999).Thus, quercetin derived from the normal diet or through supplementation may have an inhibitory effect on platelet function in vivo. 
In the present study quercetin was also shown to inhibit thrombin-induced platelet aggregation. However, as quercetin has a more potent inhibitory effect on collagenstimulated platelet aggregation than on thrombin-induced platelet aggregation, the effect of quercetin on the collagenstimulated signalling pathway was examined further. Quercetin was found to inhibit both collagen-stimulated $\mathrm{Ca}^{2+}$ mobilisation from intracellular stores and collagenstimulated whole-cell protein-tyrosine phosphorylation in a concentration-dependent manner. These processes are both essential for platelet activation and play a major role in platelet aggregation (Smith et al. 1992; Poole et al. 1997). Further investigation of the specific proteins involved in the collagen signalling pathway via the collagen receptor glycoprotein VI are required to further elucidate the role of quercetin as an inhibitor of platelet function.

The effect of a polyphenol-rich diet on platelet function was investigated by providing twenty subjects on a polyphenol-restricted diet with a lunchtime meal consisting of five portions of fruit and vegetables. The lunchtime meal was designed to contain a number of different sources of foods that were high in certain polyphenols; the levels of polyphenols in the meal are currently under investigation.

The levels of polyphenolic compounds present in the blood plasma were measured using four markers of polyphenol intake, quercetin, kaempferol, isorhamnetin and tamarixetin. In many foods quercetin is the most abundant of the flavonols and is therefore an appropriate marker of polyphenol intake. Flavonol concentrations were measured before entry into the study, as a measure of polyphenol intake under normal dietary conditions. The total plasma flavonol concentration was $0 \cdot 154 \mu \mathrm{M}$ and the quercetin concentration was $0 \cdot 1 \mu \mathrm{M}$. The total plasma concentration of the four flavonols and that of quercetin decreased by $50 \%$ after $3 \mathrm{~d}$ on the fruit- and vegetable-free diet. This effect, which has not previously been reported, could be used as a measure of compliance with the fruit- and vegetable-free diet. After the $5 \mathrm{~d}$ fruit- and vegetable-supplementation period there was a significant increase in the total plasma flavonol $(P=0.001)$ and quercetin concentrations. The total plasma flavonol concentration was twice that observed with the normal diet, suggesting that supplementation of the diet with polyphenols had been effective. The plasma concentration of quercetin was, however, relatively low. Concentrations of $1.5 \mu \mathrm{M}(\mathrm{SE} 0.39$ ) after a $7 \mathrm{~d}$ period of supplementation with onion soup containing $114 \mathrm{mg}$ quercetin (Janssen et al. 1998) and $1.34 \mu \mathrm{M}$ after supplementation of subjects with onions containing $134 \mathrm{mg}$ quercetin (Aziz et al. 1998) have been reported, while a higher plasma quercetin concentration $(3.5 \mu \mathrm{M})$ was found after subjects ingested $144 \mathrm{mg}$ pure quercetin- $4^{\prime}-O-\beta$-Dglucoside in the form of a drink (Hollman et al. 1999). The present study was designed to supplement the diet with a number of different polyphenolic compounds, in addition to the flavonoids. Thus, a measure of the total polyphenol content of the plasma samples is required.

Whole-blood platelet aggregation measured after the $3 \mathrm{~d}$ fruit- and vegetable-free period and after the $5 \mathrm{~d}$ fruit- and vegetable-supplementation period indicated no significant inhibition. However the plasma quercetin concentration after the fruit- and vegetable-supplementation period were lower than those previously reported values, whereas the levels required for the inhibition of platelet aggregation in vitro were several-fold higher. If plasma quercetin concentration had been within the range reported by Hollman et al. $(1999 ; 3 \cdot 5 \mu \mathrm{M})$ a significant reduction in platelet aggregation may have been observed. Since inhibition of platelet aggregation by quercetin has been observed with lower concentrations of agonist, a lower concentration of either ADP or collagen may have yielded clearer differences in platelet aggregation after the period of fruit and vegetable supplementation. Furthermore, the plasma total polyphenol levels could be several times higher than those of quercetin, and it has been suggested that a number of polyphenolic compounds are able to inhibit platelet function in vitro (Beretz et al. 1982; Landolfi et al. 1984), although such activity was not apparent in the current study.

Although previous studies of the effects of a diet rich in polyphenols have reported inconsistent results (Conquer et al. 1998; Keevil et al. 2000), they do suggest that certain types of food that are richer in polyphenols may inhibit platelet function. Keevil et al. (2000) used purple-grape juice, a very potent inhibitor of platelet function, as a supplement, whereas Janssen et al. (1998) used onions and reported less potent effects. In the present study a mixture of different foods that included both onions and purple-grape juice was used, but no significant effects on platelet aggregation were found. Thus, further investigation of the polyphenolic compounds present in foods that are able to inhibit platelet function, such as those found in purple-grape juice and red wine (Russo et al. 2001), is required. Grapederived products contain a variety of polyphenolic compounds such as tannins and anthocyanins, which may also be able to inhibit platelet function. Furthermore, the polyphenolic compounds found in drinks such as wine, tea and fruit juice may be more bioavailable (Hollman et al. 1997) than those in solid food matrices. This factor may contribute to the more potent inhibitory effects on platelet function seen with these foods.

It has been shown that certain polyphenolic compounds are able to inhibit platelet aggregation in vitro and that some of these compounds are more effective inhibitors than others. Whether this difference in potency is a function of structure or antioxidant activity is unknown. The precise mechanism of action of quercetin in relation to platelet function is currently under investigation. Although supplementation of the diet with foods high in certain polyphenols has been shown to inhibit platelet function in vivo, the effect of a diet rich in a variety of polyphenols has yet to be resolved. Investigation of the effects of individual polyphenols and combinations of these compounds on platelet function may explain the different outcomes that have been reported. The role of dietary polyphenolic compounds as inhibitors of platelet function remains to be fully elucidated.

\section{Acknowledgements}

G. H. was the recipient of a University of Reading Research Endowment Trust Scholarship. He would like to give special thanks to Professor Christine Williams for her 
continued support throughout his studies and Jan Luff for her help and patience during the fruit and vegetable enrichment study. He would also like to thank Rosie Barlow for her support.

\section{References}

Ader P, Wessmann A \& Wolffram S (2000) Bioavailability and metabolism of the flavonol quercetin in the pig. Free Radical Biology and Medicine 28, 1056-1067.

Aziz AA, Edwards CA, Lean MEJ \& Crozier A (1998) Absorption and excretion of conjugated flavonols, including quercetin-4'-Obeta-glucoside and isorhamnetin-4'-O-beta- glucoside by human volunteers after the consumption of onions. Free Radical Research 29, 257-269.

Beretz A, Cazenave JP \& Anton R (1982) Inhibition of aggregation and secretion of human-platelets by quercetin and other flavonoids - structure activity relationships. Agents and Actions 12, 382-387.

Born GVR (1962) Aggregation of blood platelets by adenosine diphosphate and its reversal. Nature 194, 927-929.

Bourne LC \& Rice-Evans CA (1998) Urinary detection of hydroxycinnamates and flavonoids in humans after high dietary intake of fruit. Free Radical Research 28, 429-438.

Bourne LC \& Rice-Evans CA (1999) Detecting and measuring bioavailability of phenolics and flavonoids in humans: Pharmacokinetics of urinary excretion of dietary ferulic acid. Methods in Enzymology 299, 91-106.

Bravo L (1998) Polyphenols: Chemistry, dietary sources, metabolism, and nutritional significance. Nutrition Reviews 56, 317-333.

Calzada C, Bruckdorfer KR \& Rice-Evans CA (1997) The influence of antioxidant nutrients on platelet function in healthy volunteers. Atherosclerosis 128, 97-105.

Cerbone AM, Cirillo F, Coppola A, Rise P, Stragliotto E, Galli C, Giordano M, Tremoli E \& Di Minno G (1999) Persistent impairment of platelet aggregation following cessation of a short-course dietary supplementation of moderate amounts of $n-3$ fatty acid ethyl esters. Thrombosis and Haemostasis $\mathbf{8 2}$, $128-133$.

Cicmil M, Thomas JM, Sage T, Barry FA, Leduc M, Bon C \& Gibbins JM (2000) Collagen, convulxin, and thrombin stimulate aggregation-independent tyrosine phosphorylation of CD31 in platelets. Evidence for the involvement of Src family kinases. Journal of Biological Chemistry 275, 27339-27347.

Clifford MN (1999) Chlorogenic acids and other cinnamates nature, occurrence and dietary burden. Journal of the Science of Food and Agriculture 79, 362-372.

Clifford MN (2000) Chlorogenic acids and other cinnamates nature, occurrence, dietary burden, absorption and metabolism. Journal of the Science of Food and Agriculture 80, 1033-1043.

Conquer JA, Maiani G, Azzini E, Raguzzini A \& Holub BJ (1998) Supplementation with quercetin markedly increases plasma quercetin concentration without effect on selected risk factors for heart disease in healthy subjects. Journal of Nutrition 128, 593-597.

Freedman JE, Farhat JH, Loscalzo J \& Keaney JF (1996) Platelet inhibition by alpha-tocopherol is independent of its antioxidant activity. Circulation 94, 4146Abstr.

Gibbins JM, Briddon S, Shutes A, van Vugt MJ, de Winkel JGJ, Saito T \& Watson SP (1998) The p85 subunit of phosphatidylinositol 3-kinase associates with the $\mathrm{Fc}$ receptor gamma-chain and linker for activitor of T cells (LAT) in platelets stimulated by collagen and convulxin. Journal of Biological Chemistry 273, 34437-34443.
Gibbins JM, Okuma M, Farndale R, Barnes M \& Watson SP (1997) Glycoprotein VI is the collagen receptor in platelets which underlies tyrosine phosphorylation of the Fc receptor gammachain. FEBS Letters 413, 255-259.

Hertog MGL, Feskens EJM, Hollman PCH, Katan MB \& Kromhout D (1993) Dietary antioxidant flavonoids and risk of coronary heart disease - the Zutphen Elderly Study. Lancet $\mathbf{3 4 2}$, $1007-1011$.

Hertog MGL, Hollman PCH \& Katan MB (1992) Content of potentially anticarcinogenic flavonoids of 28 vegetables and 9 fruits commonly consumed in the Netherlands. Journal of Agricultural and Food Chemistry 40, 2379-2383.

Hertog MGL, Kromhout D, Aravanis C, Blackburn H, Buzina R, Fidanza F, Giampaoli S, Jansen A, Menotti A, Nedeljkovic S, Pekkarinen M, Simic BS, Toshima H, Feskens EJM, Hollman PCH \& Katan MB (1995) Flavonoid intake and long-term risk of coronary heart-disease and cancer in the Seven Countries Study. Archives of Internal Medicine 155, 381-386.

Hertog MGL, Sweetman PM, Fehily AM, Elwood PC \& Kromhout D (1997) Antioxidant flavonols and ischemic heart disease in a Welsh population of men: The Caerphilly Study. American Journal of Clinical Nutrition 65, 1489-1494.

Hoffbrand A \& Pettit J (1995) Essential Haematology. London: Blackwell Science.

Hollman PCH \& Arts ICW (2000) Flavonols, flavones and flavanols - nature, occurrence and dietary burden. Journal of the Science of Food and Agriculture 80, 1081-1093.

Hollman PCH, Bijsman M, van Gameren Y, Cnossen EPJ, de Vries JHM \& Katan MB (1999) The sugar moiety is a major determinant of the absorption of dietary flavonoid glycosides in man. Free Radical Research 31, 569-573.

Hollman PCH, vanTrijp JMP \& Buysman M (1996) Fluorescence detection of flavonols in HPLC by postcolumn chelation with aluminum. Analytical Chemistry 68, 3511-3515.

Hollman PCH, vanTrijp JMP, Buysman M, Van der Gaag MS, Mengelers MJB, deVries JHM \& Katan MB (1997) Relative bioavailability of the antioxidant flavonoid quercetin from various foods in man. FEBS Letters 418, 152-156.

Holvoet P \& Collen D (1994) Oxidized lipoproteins in atherosclerosis and thrombosis. FASEB Journal 8, 1279-1284.

Janssen P, Mensink RP, Cox FJJ, Harryvan JL, Hovenier R, Hollman PCH \& Katan MB (1998) Effects of the flavonoids quercetin and apigenin on hemostasis in healthy volunteers: results from an in vitro and a dietary supplement study. American Journal of Clinical Nutrition 67, 255-262.

Keevil JG, Osman HE, Reed JD \& Folts JD (2000) Grape juice, but not orange juice or grapefruit juice, inhibits human platelet aggregation. Journal of Nutrition 130, 53-56.

Knekt P, Reunanen A, Jarvinen R, Seppanen R, Heliovaara M \& Aromaa A (1994) Antioxidant vitamin intake and coronary mortality in a longitudinal population study. American Journal of Epidemiology 139, 1180-1189.

Kroon PA \& Williamson G (1999) Hydroxycinnamates in plants and food: current and future perspectives. Journal of the Science of Food and Agriculture 79, 355-361.

Landolfi R, Mower RL \& Steiner M (1984) Modification of plateletfunction and arachidonic-acid metabolism by bioflavonoids structure activity relations. Biochemical Pharmacology 33, $1525-1530$.

Liu W \& Liang NC (2000) Inhibitory effect of disodium qurecetin$7,4^{\prime}$-disulfate on aggregation of pig platelets induced by thrombin and its mechanism. Acta Pharmacologica Sinica 21, 737-741.

McAnlis GT, McEneny J, Pearce J \& Young IS (1999) Absorption and antioxidant effects of quercetin from onions, in man. European Journal of Clinical Nutrition 53, 92-96.

O'Reilly JD, Sanders TAB \& Wiseman H (2000) Flavonoids protect against oxidative damage to LDL in vitro: Use in 
selection of a flavonoid rich diet and relevance to LDL oxidation resistance ex vivo? Free Radical Research 33, 419-426.

Poole A, Gibbins JM, Turner M, van Vugt MJ, van de Winkel JGJ, Saito T, Tybulewicz VLJ \& Watson SP (1997) The Fc receptor gamma-chain and the tyrosine kinase Syk are essential for activation of mouse platelets by collagen. EMBO Journal 16, 2333-2341.

Radtke J, Linseisen J \& Wolfram G (1998) Phenolic acid intake of adults in a Bavarian subgroup of the national food consumption survey. Zeitschrift fur Ernahrungswissenschaft 37, 190-197.

Rimm EB, Katan MB, Ascherio A, Stampfer MJ \& Willett WC (1996) Relation between intake of flavonoids and risk for coronary heart disease in male health professionals. Annals of Internal Medicine 125, 384-389.

Russo P, Tedesco I, Russo M, Russo GL, Venezia A \& Cicala C (2001) Effects of de-alcoholated red wine and its phenolic fractions on platelet aggregation. Nutrition Metabolism and Cardiovascular Diseases 11, 25-29.

Salonen JT, Salonen R, Seppanen K, Rintakiikka S, Kuukka M, Korpela H, Alfthan G, Kantola M \& Schalch W (1991) Effects of antioxidant supplementation on platelet-function - a randomized pair-matched, placebo-controlled, double-blind trial in men with low antioxidant status. American Journal of Clinical Nutrition 53, 1222-1229.

Serebruany VL, Lowry DR, Fuzailov SY, Levine DJ, O'Connor CM \& Gurbel PA (2000) Moderate alcohol consumption is associated with decreased platelet activity in patients presenting with acute myocardial infarction. Journal of Thrombosis and Thrombolysis 9, 229-234.

Smith JB, Selak MA, Dangelmaier C \& Daniel JL (1992) Cytosolic calcium as a second messenger for collagen-induced platelet responses. Biochemical Journal 288, 925-929.

Thorogood M (1997) Do vegetables and fruit protect against coronary heart disease? Studies among vegetarians. In Preventing Coronary Heart Disease: The Role of Antioxidants, Vegetables and Fruit: Report of an Expert Meeting, pp. 29-37 [L Rogers and I Sharp, editors]. London: The Stationery Office.

Tzeng SH, Ko WC, Ko FN \& Teng CM (1991) Inhibition of platelet-aggregation by some flavonoids. Thrombosis Research 64, 91-100.

US Department of Agriculture (1992) The Food Pyramid Guide: A Guide to Food Choice. Home and Garden Bulletin no 252. Washington, DC: US Department of Agriculture

Vinson J (1998) Flavonoids in foods as in vitro and in vivo antioxidants. Flavonoids in the Living System. New York: Plenum Press.

You KM, Jong HG \& Kim HP (1999) Inhibition of cyclooxygenase/lipoxygenase from human platelets by polyhydroxylated/ methoxylated flavonoids isolated from medicinal plants. Archives of Pharmacal Research 22, 18-24.

Zhao XY, Gu ZL, Attele AS \& Yuan CS (1999) Effects of quercetin on the release of endothelin, prostacyclin and tissue plasminogen activator from human endothelial cells in culture. Journal of Ethnopharmacology 67, 279-285. 